\title{
Understanding work, learning and the remaking of cultural practices
}

Stephen Billett, Raymond Smith and Michelle Barker (Griffith University, Australia)

\begin{abstract}
This paper focuses on dualities in both the process and outcomes of participation in work. Firstly, the process of participation in work activities and interactions draws on contributions of both individuals and the social world in ways that are variably interdependent, that is, relational. The affordances of workplaces shape the array of experiences individuals are able to access and, they in turn, elect how they engage, construe and construct what is afforded them. Both the social and individual contributions are exercisable with different degrees of intensity, focus and intentionality, thereby making the process of participation in work a relational one. Secondly, and consistent with these processes, the outcomes of workplace participation also comprise dualities. These are individuals' learning or change, on one hand, and the remaking and transformation of cultural practice that comprises work, on the other. In illuminating and elaborating these concepts, this paper draws upon the initial findings of an inquiry that is mapping the working lives of groups of three workers in each of four workplaces. The aim is to understand how these relational interdependences shape the participation, learning and remaking of work practices in these workplaces. Further, the paper identifies the exercise of both affordances and engagement for each participant within their workplaces. The findings emphasise the distinctive bases by which the groups of workers engage with their work and construct meaning and remake practice as a result of that engagement.
\end{abstract}

\section{Learning and work: remaking cultural practices}

Understanding how both learning and remaking of the cultural practices that comprise work occurs in workplaces has important practical and conceptual purposes. Practically, at a time when the requirements for work are in constant change and turmoil, there is a need to understand how individuals can best learn these changing requirements through work and throughout their working life. It seems reasonable to propose that the most likely and accessible environment to assist this learning will be workplaces themselves. The possibilities and capacities of providing effective and ongoing skill development in vocational education systems or universities can only be partial, at best. The evidence suggests that workplaces can be generative of much of the knowledge required for work performance (Fuller \& Unwin, 2002; Rogoff \& Gauvain, 1984; Scribner, 1984, 1985a). However, they also have significant limitations in terms of the distribution of opportunities for 
learning, the prospects of securing effective learning experiences and the issue of recognition of that learning (Bierema, 2001; Billett, 2001; Fuller \& Unwin, 2003; Solomon, 1999). Much research has been undertaken to understand whether particular instructional strategies can be adapted to workplaces and through this has come an increasing emphasis on mentoring and guided learning in the workplace (e.g. Billett, 2001; Fuller \& Unwin, 2003). This is all well and good. At least some evidence suggests that this kind of learning support is particularly helpful in securing knowledge that will not be learnt through workers' solitary discovery activities. Nevertheless, the key premises that underpin both learning through engagement in everyday work activities and interactions, and through intentional learning strategies are those associated with the degree of affordances (e.g. support, opportunities, interactions, guidance) provided by the workplace, and also the degree and bases by which individuals engage in the workplace (Billett, 2004), that is, how individuals and workplaces exercise their agency in shaping participation in and learning through work. Important issues that arise include, how these contributions are negotiated, and then construed, constructed and engaged by individuals. Consequently, a related practical concern is that individuals' learning is neither a wholly solitary nor a wholly socialised process. Moreover, more than learning through this process, individuals are actively remaking and potentially transforming their work practices and activities. So not only is there a legacy in terms of ontogenetic development -- individuals’ development across the lifespan -- but also in terms of situated practice, which in turn shapes the cultural practices (Leontyev, 1981), including those comprising paid work (Billett, 2005b; Rogoff, 1990).

There are also important conceptual issues being worked through here. Currently, there is much interest in the relations between the social and individual within psychology (Rogoff, 1995; Scribner, 1997/1990; Valsiner, 1994), philosophy (Archer, 2000; Bhaskar, 1998) and sociology (Fenwick, 1998; Giddens, 1991). Although different in emphasis, much of these deliberations privilege one or the other of these contributions (i.e. social structures or individual agency). Such debates address important issues associated with the origins of the knowledge and the knowing required for work, and whether and in what ways the individual or the social precipitates the formation (including its remaking and transformation) and learning of this knowledge. That is, do individuals bring about personal and cultural change, or is that change dependent upon social forms and structures (Ratner, 2000; Valsiner, 2000), or some relationship between the two? Workplaces provide a useful test bench to investigate, illuminate and discuss these issues. This is because they comprise environments where social structures are enacted, and knowledge that has historical and cultural geneses is manifested and engaged with by individuals, albeit mediated by their unique personal histories. In workplaces there is also a necessary duality in the form of an interdependence between the social and the individual, because each is dependent upon the other for their continuity 
and development (Billett, 2005b). This interdependence resides in the relationship between the social suggestion and agency manifested in the workplace, in terms of norms, practices and concepts: institutional facts (Searle, 1995), on one hand, and, on the other, individuals' intentions and agency as shaped through their ontogenetic development. This interdependence is held to be relational because of the contributions are unlikely to be balanced equally. They may be based in relationships of mutual effort or supportive co-participation their interpretation and engagement will not be equally arrayed (Malle et al 2001). Equally, it may be based in relationships marked by coercion (Valsiner 1998) or disengagement (Williams 2002).

In exploring these propositions, this paper first discusses the interdependence between social and individual agency as a means to understand learning through and for work and the remaking of cultural practices. Next is a description and discussion of the procedures, participants and findings of the study examining the working lives of 12 workers, employed in four distinct workplaces. The findings are elaborated in sections discussing the bases of affordances and engagement in each workplace. In particular, the findings illustrate how for each individual their learning and remaking of cultural practices are intertwined in their goals, preferences and intentions, and the social suggestion of the workplace in terms of its affordances and press.

\section{Interdependence between social suggestion and individual agency at work}

The key premise of duality comprising relational interdependencies is that neither the social suggestion nor individuals’ agency alone is sufficient to promote learning and the remaking of the cultural practices that constitute work. The social suggestion or press comprising societal norms, practices and values, and their enactment in instances of social practices such as workplaces, is never complete or comprehensive enough to secure socialisation. Here, socialisation is defined as the unquestioned and comprehensive passage of knowledge from the social world to the individual. As Newman, Griffin and Cole (1989) propose, if the social world was able to project its message unequivocally, there would be little need to communicate. This is because understandings would be implicit, not requiring further communication to be construed and comprehended. However, as Berger and Luckman (1967) and others propose, the social suggestion is not projectable in a way likely to lead to socialisation because individuals will engage with the suggestion with greater or lesser reception, and greater or lesser fidelity in its appropriation. The limitations of the social suggestion, means individuals necessarily have to be agentic and active in the construction of meaning. If for no other reason this is because what the social world project requires interpreting and construing to understand what is being suggested. Yet, beyond attending to, engaging with and comprehending what is being suggested, individuals also bring a possibly unique base of conceptions, procedures and values to their engagement with social forms and practices. 
These conceptual premises seem particularly salient for understanding the learning through participation in the cultural practices comprising paid work. Much of knowledge needing to be learnt for paid work has its origins in cultural practices and historical precedents (Scribner, 1985b). This knowledge arises from a cultural need and has been refined overtime through its enactments. Consequently, interaction with the social world is required to access this knowledge because it does not arise from within individuals. Moreover, when individuals engage with this knowledge, they also engage in a process of remaking these cultural practices at particular points in time and through access to particular forms of social suggestion. This learning and remaking of practice is not through some faithful and mechanical reproduction of what is being suggested socially. It occurs through individuals' engagement, construal of and construction of those practices, albeit mediated by the exercise of social and cultural norms and practices. Moreover, the exercise of this personal agency (i.e. its intensity and focus) is essential in transforming cultural practices as new cultural needs arise, such as those brought about by changing times or technologies. In considering this process, Wertsch (1998) distinguishes between either compliant learning (i.e. mastery) that is superficial and can be the product of forceful or compelling social suggestion and learning in which individuals engage willingly (i.e. appropriation) because of a concurrence between what is experienced and individuals' values and beliefs. Richer or deeper kinds of learning requires effortful engagement buoyed by individuals’ interests and intentionality (Malle, Moses, \& Baldwin, 2001). Such learning is most likely to occur when individuals engage actively in the process. So, the first key premise is of an inevitable interdependency between the agency of the social world in projecting its suggestion and that of individuals in making sense of what is suggested to or afforded them. At the heart of this interdependency is individuals' agency and intentionality, premised upon their identities and subjectivities.

A second reason to bring individuals' agency to the forefront of considerations about their learning and the remaking of culture, is the likely person-dependence in these processes. Individuals' construal of what they encounter is uniquely shaped through a lifetime of negotiations with the social suggestion. These negotiations are encountered through the myriad social practices individuals engage in throughout their lives that microgenetically (Rogoff, 1990; Scribner, 1985b) moment-by-moment --contribute to their processes of thinking and acting throughout their life history: ontogenetically. The process that Piaget (1968) referred to as securing equilibrium, and more recently von Glasersfeld (1987) refers to as maintaining viability comprises an enduring personal epistemological process. This active process of sense-making is premised on an expectation of variability and inconsistency in the negotiations with the social world. Individuals learn from the earliest age to expect variability rather than consistency from the social world (Baldwin, 1894). Hence, rather than being mere recipients of the social suggestion, individuals 
engage in a process of active appraisal of what is being suggested. Therefore, claims about mastery and appropriation leading to particular and more or less valued kinds of learning need to be treated sceptically. Being confronted by something that is inconsistent with individuals' beliefs may indeed lead to rich learning, because that inconsistency with existing knowledge and/or beliefs may have to be addressed, reconciled or it may, in turn, transform individuals' existing knowledge. Conversely, appropriation might result in the uncritical acceptance of existing practice (e.g. the marginalisation of certain individuals or groups). So appropriation might be analogous to Piaget's (1968) concept of assimilation -- the social suggestion being integrated with what is already known -- through individuals actively seeking to appropriate new social suggestion, whereas mastery might enact accommodation or change in categories of knowledge structures and ways of knowing. This is because individuals exercise intentionality in making sense of much of the social suggestion through a history of such socially based, but agentically engaged experiences. Hence, individuals' ontogenetic development arises through a personally agentic epistemological process shaped through ongoing interactions with social world that subsequently influences how they engage with new experiences. Because these experiences are likely to be unique to individuals, they are highly generative of new constructions in ways described as inter-psychological (Vygotsky 1978). Given that these experiences lead to intra-psychological attributes, there will inevitably be personally distinct conceptions, as well as areas of commonality or shared understanding with others in their process of knowledge construction and remaking of cultural practices.

So thirdly, because of ontogenetic legacy and personal epistemology, consideration needs to be given to individuals' pre-mediate experiences_-those that come earlier. It is these experiences that are held to shape their conceptions and subjectivities - gaze, if you like - and, consequently, how they construe subsequent experiences. Further, it is these conceptions and subjectivities that shape individuals' intentionality and agency in the processes of their learning and the remaking and transformation of cultural practices. These pre-mediate experiences are shaped by and contribute to unique patterns of personal epistemology. Even the most apparently uniform social experience will be the subject of interpretation, construal and construction of particular personal social kind. So, life histories comprising individuals’ prior social experiences are an important premise to how they engage with the world.

Finally, the relationship between individual and social agency is not mutual or reciprocal: it is relational. Just as the social suggestion can be either weaker or stronger, so too can be individuals engagement with a particular social suggestion (e.g. situated practice, cultural norm, cultural practice). The prospects for the coming together and contributions of the individual and social being enacted in equal parts, or ways that are equally shared is quite remote. The very interactive processes arising will be individually unique in some ways. Individuals may be selective in their 
reading of a particular social suggestion or simply be unaware of it (Billett, 2005b). So central to the interdependence between social and individual is that it is rendered relational as individuals encounter social experiences projected in multitudinous and diverse forms and construct meaning from ontogenetically diverse bases.

This relational interdependence is continually being negotiated as both social and individual intentions, and their relations are transformed. Here, a key role is exercised agentically by individuals' sense of self or identity. Rose's (1990) concept of the 'enterprising self', the individual entrepreneur whose focus and direction is towards self-regulation and individualisation aimed at securing the employers' economic goals and, therefore, securing their relations as an employee, provides an instance of this kind of agency. Yet, inherently individually constructed sets of intentions can be characterised by resistance to or the clever manipulation of the regulatory practices of the workplace, as much as either unquestioning compliance to them. That is, the exercise of agency may not always be directed towards securing further social subjugation or faithfully reproducing existing subjectivities. Instead, it may focus sharply on securing more personal goals.

\section{Procedures}

In order to understand more clearly the relations that underpin the interdependencies at work and their consequences, we decided to investigate the working lives of groups of three workers in each of four different kinds of occupations and workplaces. The reason for selecting three workers was to gain insights into differences in how affordances or invitational qualities were exercised towards workers in the same workplace; how these workers then construed and constructed what was afforded them; and how they engaged in their work and learned as result of these processes. Previously, we investigated individual workers in three workplaces to understand the continuities of both the workplace and individuals (Billett, Barker, \& Hernon-Tinning, 2004). That earlier study identified the negotiated bases for participation in the workplace. This study provides an account of how different workplaces afforded opportunities for workers and, in turn, how workers engaged with what was afforded them. Here, the goal is to examine what, if any, differences arise in terms of workplace affordances and individuals' engagement, and to draw comparisons or contrasts across four different kinds of work and workplaces. In selecting the work sites, we wanted to gather data from sites that have different purposes, organisational structures and patterns of employment. Earlier research (e.g. (Grey, 1994)) indicated how institutional rules and practices can have a significant impact upon the kinds of workplace participatory practices. Therefore, we engaged with workplaces with different kinds of participatory practices and work, including some utilising technology and also teamwork, in order to gain insights in diverse work situations and participatory 
practices. Another consideration was to capture data about workers, whose employment standing and status were diverse in terms of employment, standing of work and connectivity. The four workplaces that were selected, contacted and agreed to participate are: (i) a gymnasium; (ii) a restaurant; (iii) an Information Technology (IT) support section within a university; and (iv) a fire station. In each of these workplaces, three individuals agreed to participate. In the gymnasium -Trim and Healthy -- they comprised a receptionist, a trainer and a manager. In the restaurant -Platinum -- they comprised a chef, who is also a part owner, a waitress and a manager, who is also a part owner. In the IT support section the participants comprised three helpdesk consultants, one of whom is a manager. In the fire station, the participants comprised a station manager, and two fire officers, one of whom is a specialist officer.

The procedures comprised a series of interviews continuing over an 18-month period. The data gathering commenced with two lengthy semi-structured interviews, the first focusing primarily on the workplaces, their requirements for continuity and their norms and practices. The second interview focused primarily on the workers' history and personal preferences. These lengthy interviews, taped and transcribed, were used to understand the affordances of the workplace and its practices: what constitutes their institutional facts (Searle, 1995) and bases for workers’ participation in and learning for their work. Beyond these two initial interviews will be a series of progress interviews occurring over a 12-month period. Here, the focus is on the first two interviews for each of the 12 participants. Accordingly, the findings are organised under sections that focus on the duality of the process of workplace affordances and engagement, and then outcomes in terms of individual development and the remaking of the work practices.

\section{Processes of affordances and engagement}

The four workplaces provide quite different instances of participatory practices. That is, their bases of affordances and engagement are quite distinct. The fire service officers' work pattern comprises long shifts during which the fire officers work, eat and sleep (i.e. live) at the fire station. Their work can include the kinds of exciting and demanding emergency tasks that attract high public praise and afford a public status that the fire officers report as being important to their identity. There are other more mundane tasks, which see officers out in the community checking buildings and fire systems, or improving their capacities to perform during emergency incidents through training exercises. So, as part of their engagement in emergency duties there are ample opportunities for developing further their skills through practice and also engagement in courses whose successful completion is a pre-requisite for promotion. Living and working together in shift rosters also affords the opportunity for these officers to develop the capacities to work effectively in teams, particularly in emergency situations. Team culture is importantly grounded, among other things, in responsiveness 
to the command and control authority that prioritises colleagues' safety, care and responsibility in emergency situations. There is evidence of a high level of intersubjectivity or shared understanding among the informants about their work and its conduct that appears to arise from the extensive and close working relationships among the shift.

Moreover, many of the fire officers have second jobs during extended periods of non-duty time on a shift's roster. Hence, they are afforded options not widely afforded other workers. Working for a large organisation that has emergency services as its sole function also affords opportunities for specific promotion and advancement, and options for less physically demanding work later in fire officers' working life. Furthermore, one of the three fire officers was permitted to work from home as he cares for his sick wife. However, it was claimed that such a large public sector organisation also allowed some officers to abrogate their responsibilities to their work and co-workers. Sometimes, it is claimed, they were too focussed on a second form of employment. Yet, while the workplace afforded this circumstance and could do little to correct it, the work practices of extensive and long periods of close engagement also provided a vehicle for individuals to be labelled as lazy or incompetent. Such labels, once attached, were reportedly very difficult to remove. Significantly perhaps, none of the interviewees expressed significant concerns about their working lives or indicated any intention to seek employment outside the fire service. Quite the contrary; employment in the fire service is seen as a strong foundation on which to build a financially secure and personally rewarding future Their goals for engagement in their work were generally about improving their performance or prospects for promotion, yet in ways that permits them to remain active fire fighters. There was a common concern about avoiding the kinds of promotion that would take them away from emergency work. So, there seem to be considerable consonance between these individuals' working life goals and what was afforded by the workplace.

The IT helpdesk also represents a working situation that had many of the work life qualities of working in a large organisation and as a member of a small to medium-size team. The IT support staff rotate through tasks associated with responding to requests for technical assistance from university employees and students. They also have individual project work and specialist tasks. They are all physically located in a rather cramped open working space, except when in the Call Centre room. Like the fire officers, there is also a reliance on other workers because problems that arise often require solutions that others may know about or need to know about. There are opportunities for training and development in technology available to these workers and promotion. Yet, like the fire fighters, there are concerns about being promoted outside of active IT work. On the surface, there seems to be a high level camaraderie among the IT workers in their shared space, often manifesting itself in banter. There are also social events that occur outside of work time in which staff members participate. In contrast to the fire officers, the unifying bases for their work 
derives less from personally shared practices and values, and more on a standard operating environment (SOE) under which the computing work of the university operates. This SOE acts to homogenise the tasks of client problem solving to a narrow range of systemised acceptable solutions. These solutions are prepared and shared through the rotation of so called mundane duties associated with client personal computer (PC) support. There are also electronic monitoring devices that capture elements of these workers' performance in a public and (perhaps too) quantifiable way. Each time a university staff member requests assistance from IT support, a job or task is lodged electronically. Next, the staff member who requested help receives an email stating a job number. When the task is completed the staff member is asked to provide brief evaluation of their satisfaction with the help they received. The evaluation report is provided to rate the performance of help desk workers.

However, the sense is that shared understanding, beyond the mechanics of the standard operating environment, is less evident than with the fire fighters. Understanding about work seemed more grounded in the individual's values and beliefs. Their engagement differs. For example, Sid, the manager, reported being fully engaged in the both the workplace environment and its social events. Although he had been the subject of significant workplace affordances (i.e. employment support, training, patronage), another helpdesk worker, Bob, was actively seeking employment in a different area within the university. He reported avoiding unnecessary social interactions. Dick, the third helpdesk worker, while engaging in his work effortfully, reported being disengaged from the working group and disillusioned by how the workplace affordances were distributed among his colleagues. Certainly, in different ways, the electronically generated information about work performance, was seen as being a negative affordance that led to inevitable comparisons and criticisms of colleagues. It was claimed that the workplace supported individuals who were poor performers and the promotional opportunities favoured those who were self-promoters.

The IT helpdesk staff all had quite diverse prior experience and employment practices. Sid, had previous experience in information technology support in the public service before being employed by the university. He was offered casual work first before being given a full-time position. Dick, with an electronics training and background, had a long career within the university and has watched the information technology functio evolve over many years. Bob was previously a builder whose engagement with the university was through a government funded retraining program. Thus, the backgrounds of each worker, their means of providing their current work and their level of engagement was far from uniform across the three IT support workers.

The participants in the restaurant were a part-time waitress, and two of the three part-owners of the business Whereas there were relatively uniform bases for affordances for the fire officers and IT workers, there were distinct premises for the three restaurant workers' engagement in their work. 
Two were enacting their desires to be managers of businesses in the catering area. The workplace afforded them the opportunity to exercise their vocation. The third participant, Rosie, was a parttime waitress whose employment funded her university studies. The exacting requirements and high standard of work and engagement with customers that were key workplace goals provided quite different affordances for these three participants. For John, the senior part-owner, it represented the kind of work to which he was well suited and from which he derived personal and professional fulfilment. He was looking to expand his competence in the organisation and management of catering and hospitality events. For the other part owner, Robert, this experience was developing further his cooking skills, and more importantly his restaurant management skills. These were key to his future work aspirations. In this way, the challenges he faces are often perceived and welcomed by him as opportunities to learn new skills. However, while conscientious and hard working, Rosie experienced the demands of the restaurant and the exacting level of commitment as being less invitational than did John or Robert. Rosie's vocation resided elsewhere. In this way, engagement in this workplace was premised quite differently. For John, it had been about establishing a business of which he could be in control. For Robert, participation in this workplace was a product of buying a share of the restaurant. For Rosie, it was a question of trading time for remuneration to sustain activities outside the workplace that were closer to her personal goals.

The gymnasium offered some of the benefits of working in a large organisation, because it was one of the chain of the gymnasiums, yet also had a familial basis for participation. This extended to part-time workers. For instance, the part-time receptionist, Jane, although under 20, has had a long association with the gym as both a client and a part-time worker. Moreover, she had a longstanding friendship with the manager. As part of her employment conditions, Jane was afforded free gym membership. In addition, and unlike Rosie, because she was studying physiotherapy at university there was some consonance between her part-time work in the gymnasium, her studies and ultimate career objective of becoming a physiotherapist. This part-time worker could increase her hours of employment if she so desired and was promised security of employment throughout her years of study. In this way, the workplace affordances do much to support Jane's needs and career goals. The manager, Marilyn, also had a long association with the gym and had retained her position as manager when its ownership was transferred to a chain of gymnasiums. Her career goals were sustained by this takeover and it offered her the prospect of promotion to a more senior position within the gym chain. Her current status enabled her to work with the regional manager and owner, thus providing opportunities to learn more about gym administration. The third participant at the gymnasium, Hayden, acknowledged different kinds of affordances and their change over time. He was a self-employed personal trainer conducting one- on- one sessions with his clients, and a gym employee trainer assisting members with their fitness programs. Hayden was 
also a part-time student. For his personal clients, Hayden is afforded access to the gym and its facilities on the basis of payment to the gym. Yet, there was significant reciprocity in the relationship. The better service he provided, the greater retention of membership within the gym. This retention and expansion of membership are the key bases for the gym's survival and development. So, the gym provided him with access to potential clients, and the quality of his work with those clients contributed to them maintaining gym membership. Hayden has established a level of clients he wishes to secure and develop as the foundation for his personal training business. This arrangement will remain in place until such time as his personal client base is sufficiently large enough to warrant his ceasing to work as an employee. This will be most likely achieved through a positive relationship with the gym. Similar to Jane, there was also some consonance between Hayden’s part-time work in the gymnasium, and his university studies in Leisure Management. Moreover, the policies of new owners have lead to him upgrading his trainer qualifications that also links him closely to the gym, as it now requires staff to be trained.

This description shows that there are quite different premises that shape these workplace affordances and their construal by individuals. The fire service provides its officers a form of work which is seen currently as exciting, high profile and one that enjoys, apparently, unprecedented high standing in the community. Hugh, one of the fire officers, referred to the transformation of his standing in the community upon becoming a fire officer: being invited by those who previously ignored him in the pub to engage in conversation. Others commented that their work enjoys a higher status than that of police and ambulance workers. Bruce referred to being frequently waved to by members of the public when in a fire engine. Moreover, the work conditions, hours and extended periods of non-work time, mean the fire officers can have a satisfying, productive, (and even second income-generating) life outside of the fire service.

As noted, all three fire officers were seeking to embed themselves further in their workplace, its culture and its affordances. The interviews identified considerable levels of intersubjectivity in their conceptions of their work and work-related values. The extent of this and its source may well be the intensity, duration and shared nature of their working lives. This level of intersubjectivity was less evident for the IT help desk workers. Although engaged in shared work and a shared work environment underpinned by a standard operating system, there were distinct dissonances and differences in perspectives arising from their work. Their personal and professional trajectories were also quite distinct. Two of the three articulated concerns about and exercise distance from the allegedly shared values and social interactions of the workplace. So, unlike the fire fighters, whose trajectories were more centripetal, the IT workers' trajectories were towards more peripheral participation, in so far as the team functioning was concerned. The gym presented as an environment where there is shared interests and concerns among the three workers, albeit without 
the range of institutional affordances of the fire station or the university. Here, there were both consonances and a coalescing of work-related practice in values and those associated with individual intention and agency. The individual goals of the manager, part-time receptionist and personal trainer were intertwined with those of the workplace. In particular, the personal trainer characterises what is referred to as a contingent worker -- not formally tenured within the workplace. Yet, Hayden and Jane enjoyed engagement in and reciprocity between the activities in the workplace and their personal goals. Similarly, for the part-owners of the restaurant (John and Robert), their workplace afforded them important opportunities associated with their personal and professional trajectories. However, for Rosie the waitress, only her personal goals of securing income were to be secured, for her key interests lay outside of the workplace.

Sitting within this analysis is evidence of interdependence between what is afforded individuals and individual engagement with it. For instance, even in the fire service there were quite distinct constructions of the purposes and practices of the command and control ethos that underpins emergency service work. These were seen as being helpful when they ordered the activities of fire officers in emergency incidents. Yet, the officers themselves identified distinct construal in their responses to these requirements. For instance, Bruce the station manager, who, by rank is automatically appointed incident controller in an emergency response, lauded the command and control ethos for its operational efficacy. Yet, at the same time, he derided its enactment upon him by more senior administrators. Also, Ian referred to having considerable autonomy in emergency situations because of his specialist expertise. So, although he might be given a general direction by the incident controller, he claimed to exercise considerable autonomy in the conduct of his work. Hugh also referred to enjoying the capacity to direct his own work and not be constrained by the decisions of others. He noted the long process it had taken for him to be employed as a fire fighter, despite the fact that he was already trained as a fire officer in the United Kingdom. He felt this process had wasted time and was now engaged in intentional learning to attain the level of seniority through promotion that his experience and skills warranted.

So even in the most regulated of work, these practices were not enacted without the agency of the individual. Although working under the direction of an incident controller in an emergency situation, there is individual discretion. It is a discretionary power that is exercised, albeit within an institutional practice that distributes this autonomy in particular, and sometimes, institutional ways. Ian's comments exemplify this. Perhaps it is within the space provided for these individuals to exercise this discretion when engaging in dangerous and confronting work, and that their reported desire for leadership can be exercised.

Within the information technology work there were clear differences in how affordances were interpreted and engaged. What for Sid was an openly social working environment that 
welcomed and embraced workers and extended to after hours social activities, was seen quite differently by the two other colleagues. Bob expressed a preference for keeping his work and social life quite separate and, therefore, would not engage in social exchanges other than those required to conduct his work. Dick elected to participate even more peripherally, to avoid unnecessary social interaction. This may have being because of a previous workplace incident. However, despite different kinds of participation it was underpinned by distinct goals and intentions that were found in previous or premediate experiences. In a distinctly different way in the gym, it was how the workplace offered the different affordances to workers that were central to their engagement and participation. It offered them quite different invitations to engage and work. Yet, because of the consonance between these affordances and their personal trajectories, the affordances were seen to be welcoming and highly invitational.

\section{Individual learning and the remaking of work practice}

As individuals participate in their workplaces they are also engaging in learning work. This learning work comprises two dimensions. The first is individual learning and, the other the remaking of cultural practices that comprises their work. Much of the fireman's work is explicitly about learning: learning to improve their practice, learning to be more knowledgeable about the likely sources of fire, learning about how best to prevent fire from occurring. They are engaged in a continuous cycle of technical preparation and maintaining readiness to act, which is all about learning the practice of responding to emergency incidents. Moreover, the workplace provides an environment in which this learning is supported, but engaged with by the fire fighters through their individual and shared activities. It is through their collective experiences and actions that they conduct their work and in ways that are likely to be quite distinct from earlier and other fire fighters. For instance, there is a drop in the number of fires arising from more safely constructed buildings, fire prevention strategies, and fire and smoke alarms. Consequently, the fire fighting aspect of their work has declined, yet new applications for their skills have emerged in responding to accident scenes. Much of their new training is directed towards such scenarios. So, here there is explicit and institutionally supported the remaking of cultural practice, albeit in a particular work context and point of time. Hugh notes the difference between the work and practices of fire fighters in Australia and those in Wales were he used to work, for instance.

In a similar way, the IT workers are engaged in processes of learning. Because their work comprises addressing emerging problems, establishing systems, refining those systems and engaging in the implementation of new systems, much of their work is inherently about learning and maintaining their competence in their work, yet also the remaking of practices in particular circumstances. Analogous to the fire fighters' circumstances, there are changes in core aspects of 
their work. The improved and more reliable performance of computers means that hardware failures are becoming less and less frequent. At the same time, software applications their maintenance and updating are becoming more and more complex. Given the decline in hardware failures, increasingly remote IT support work is able to address the majority of users' computer based problems. So, these changes mean that like the fire fighters, these information technology workers are actively engaged in the process of remaking the practice of what constitutes an information technology technician. However, there are some distinct differences between the learning work of the fire fighters and those of the IT workers. The fire fighters work for an organisation whose purposes are inherently about emergency services. Their promotion and well-being is vested in their perfect performance of their work. There is also a uniquely essential quality about working with others in moments of extreme emergency and a requirement for effective performance that in some ways transcends the requirements of individual preferences for the conduct of work. So, being together and working together is important. The IT workers are not so pressed towards potent and collective goals. Much of their learning appears to be underpinned by them being as much disengaged from the shared practice as engaged with the shared practice. They also work in an environment that is reliant upon information technology, but where this work is third or fourth in the tiers of importance. For instance, a senior manager in the IT area referred to these workers as 'bottom feeders'.

So, the levels of engagement across the two workplaces that have strong team qualities are quite distinct. Moreover, perhaps most sharply marked in the IT workplace are differences in affordances and engagement. Yes, there are significant differences within the fire fighting workplace. Ian is committed to work from home, Hugh is required to undertake training and recognition of prior learning processes to have his fire fighting skills recognised. But, the firefighters' learning and working is directed towards centripetal participation. This is less true of the IT help desk workers, whose modes of participation and engagement are directed variously towards being peripheral, to find a new practice to participate in, as well as centripetal participation. Consistent here though was individuals actively engaged in remaking work and work practice. The fire officers were constantly engaged in refining the existing practices and extending their skills to new areas, albeit how to extract victims from motor vehicle crashes, to learning more of the layouts of local businesses and offices, to inspecting properties for fire risk. The help desk workers were also engaged in remaking the practice of information technology support through remote access technology and implementation of a standard operating environment.

The learning work of the other two workplaces is also shaped by interaction between individual's personal goals and the workplace's affordances. The learning work in the restaurant for John is all about developing further his business as both a restaurant and as an outside caterer. In the 
exercise of his work he's learning to improve and extend his vocation. His new emphasis on management is even leading him to consider shifting from hospitality work, which has been the key source of his employment and sense of identity to date. Moreover, Robert is engaged in learning work as developing capacities associated with dealing with the members of the public and others. This comprises a personal short-term goal in terms of improving workplace efficacy, but also a more long-term goal about owning his own restaurant. However, the learning work of Rosie the waitress is more about fulfilling the demands of her employer to the degree that she can maintain employment, thereby sustaining her other activities. The learning work of those in the gym is also varied. In different ways they are afforded particular opportunities, including those explicitly about learning. Marilyn is able to extend her skills and prospects through interacting with managers in other gymnasiums and the owner of the business. Hayden is also able to extend his knowledge through building up a diverse clientele and through engaging in an educational program about health and fitness coaching and leisure management. Jane also learns through her work so that she can maintain that employment. Yet, unlike Rosie the waitress, she is able to apply or grow her knowledge of physiotherapy through her paid part-time work. In these ways, learning and work are explicitly linked. However, the bases for, process of and outcomes of these experiences are different and in some ways quite distinct. These differences are not simply a product of immediate social factors; they are product also of the individuals' interests and agency. Here also are individuals actively engaged in remaking work and work practice. The restaurant staff are engaged in being responsive to a particular clienteles need at and through a particular level of food service. Similarly, although perhaps not entirely novel, the workers in the gym work by remaking practices in their workplace under the arrangements set out by their new owner.

\section{Relational bases of work and learning}

This analysis of these four groups of workers indicates how distinctly the workplace provides affordances and in turn, how those affordances are engaged with, construed and constructed by individuals as exercised through their intentionality. These are relationally interdependent bases for learning through work and the remaking of cultural practices. The dualities here are not simple. They are richly interconnected and intertwined. The process and outcomes of engaging in work activities is more than the completion of tasks and interactions. For many, it is the means through which their identity is shaped and exercised (Noon \& Blyton, 1997; Pusey, 2003). The worth to individuals’ identity appears to me more than positioning amongst socially preferred and acknowledged forms of work. Presumably, if this was the case only those employed in the most prestigious and highest-paid work would feel any sense of fulfilment in their work, while the rest would be disillusioned and disempowered by their relative standing on such an externally mediated 
measure. However, rather than being wholly externally mediated, individuals' interests seem to reside in work may be perceived as having low standing by others. The societal value and standing granted to fire fighters is something generated outside of their workplace, but manifested in the practice and public execution of their work. The apparently contradictory mix of adherence to command and control protocols, yet afforded freedom to have second forms of employment are other nuanced and relational bases for these workers to be highly integrated with their work practices and its culture. In some ways, the work demands it. Yet, clearly some contravene that by being seen not to be committed to their work, thereby raising questions about their competence and its importance to individuals' sense of self.

One way of understanding the importance of and links between self and work is through the proposition that the process of engagement in work activities necessarily engages individuals in ongoing and moment-by-moment individual learning (Rogoff, 1990). Therefore, engagement in work of any kind leads to particular and possibly significant legacies in terms of individuals' development that is generative of close links between individuals' sense of self and their work. That is, work and learning are so intertwined as to inevitably link individuals to their work activities (Fenwick, 2002; Somerville, 2002). This work may not always be viewed positively by the individuals so engaged, but there is, nevertheless, a cognitive legacy and inevitable links to individuals' sense of self.

So, concepts, procedures and values are initially learnt, reinforced and transformed through engagement in work activities. The workplace provides an environment that is rich in its contributions to individuals' learning as they engage in work activities and, in doing so, remake the cultural practices that comprise paid work (Hodkinson and Hodkinson, 2003; Somerville \& Bernoth, 2001). The privileging of environments in which to learn is not whether they are sites that promote learning as their key purpose, but the degree by which they provide the inter-psychological experiences of activities and interactions through which knowledge is experienced, accessed, engaged with and constructed. These environments are perhaps most potent when supported by the assistance of another who understands that knowledge and can work to make accessible what is otherwise inaccessible, and support and monitor that learning (Billett, 2005a). These affordances or invitational qualities are central to what constitutes a learning environment. Nevertheless, central to this process of learning what constitutes a learning environment is also the degree by which individuals act agentically in the process of constructing knowledge (Billett, 2005b; Billett \& Somerville, 2004). This epistemological agency (Smith, 2004) comprises individuals' construal of what they experience (e.g. what constitutes welcomed or unwelcomed affordances), the degree of intentionality in their engagement in those affordances (e.g. activities and interactions) and their construction of meaning, procedures and values. This epistemological agency is seen as having two 
dimensions. Firstly, there is intentionality -- that is the focus and direction of the engagement by individuals with what is experienced socially. Then, there is the degree of intensity -- priority and potency of the exercise of individuals' agency and agentic action. The diversity of interests and motivations that personally mediate the twelve workers' engagement in their work evidences personal epistemology as a strong relational base of work and learning practices.

So individuals' learning, often the refinement of what is already known or its reinforcement, arises through their engagement in everyday conscious thought through what constitutes their personal epistemology (Bauer, Festner, Gruber, Harteis, \& Heid, 2004; Smith, 2004). Indeed epistemology is itself shaped through a history of relations and interactions with the social world, throughout ontogeny (Scribner, 1985b). Transformational learning can also arise through engaging in new activities and interactions, such as those in turbulent times of employment, or other experiences that confront individuals with perturbations requiring new insights (Rogoff, 1990), novel procedures or diverse values (Somerville, 2002). These learning processes have parallel and analogous consequences for the cultural practices that comprise paid work. That is, as individuals engage even in the most routine form of learning they are participating in the process of remaking cultural practices. Culture and society are remade and transformed as individuals engage with their practices, learn and construct them at particular points in their personal histories and points in time (Billett \& Somerville, 2004; Leontyev, 1981). The new management of the Gym, the growth of the Restaurant catering business, the decline in the number of fire emergencies and the increasing reliability of computing facility are all instances that reveal the relational interdependence of individual engagement and changing cultural practice at work. Central to that learning and remaking of culture is the degree by which individual agency directs, engages and constructs what they experience: their epistemological agency which is shaped by individuals' sense of self (Billett \& Pavlova, 2003; Billett \& Somerville, 2004; Somerville, 2002).

Consequently, continuities and transformations in work and individuals’ learning are linked to how individuals construe, engage in and construct the activities and interaction that comprise the historical, cultural and situational contributions that constitutes the gift of the social (Archer, 2000; Cole, 1998; Scribner, 1985b): the norms, values, practices that are accessible in and projected by the social world. Further, individual contributions to thinking and acting (individual agency and intentionality) are associated with and shape their identities and subjectivities or sense of self. In other words, there is relational interdependence between individual and social contributions to thinking and acting that evidence learning (e.g. (Valsiner \& van der Veer, 2000).

The personal histories of the help desk workers are exercised in different ways within work that is hidden from many of those who benefit from it. Instead of public adulation and support (as in the case of the fire officers), some of these workers rely on electronic feedback from client surveys as a 
means to demonstrate their worth. Equally, the workers in the gymnasium and the restaurant are seeking quite different bases for their continuity and confirmation of their being effective through that work that shapes their intentions and agency. For some, this comes from within the workplace, but for others it comes from outside of it.

In all, these findings demonstrates how work and learning work are integrated in different ways and different purposes across these four workplaces. It emphasises the relational nature of the interdependencies between the social and individual contributions, and illuminates how the confluence of the social and individual is exercised perhaps most strongly by individuals' construal and construction (learning if you like). The social practice is as much dependent on these individuals as individuals upon it. Hence, even from the perspective of the remaking of cultural practices, such as in those skills required for workplaces, individual agency stands as an important component and needs to be considered by pragmatic agendas currently associated with learning and learning throughout working life.

Acknowledgement: The authors acknowledge the support provided by the Australian Research Council to conduct the research reported here. Also, the authors appreciate the detailed and helpful comments provided by the reviewers.

\section{References}

Archer, M. S. (2000). Being Human: the problem of agency. Cambridge: Cambridge University Press.

Baldwin, J., M. (1894). Personality-Suggestion. Psychological Review, 1, 274-279.

Bauer, J., Festner, D., Gruber, H., Harteis, C., \& Heid, H. (2004). The effects of epistemological beliefs on workplace learning. Journal of Workplace Learning, 16(5), 284-292.

Berger, P. L., \& Luckman, T. (1967). The Social Construction of Reality. Harmondsworth, Middlesex: Penguin Books.

Bhaskar, R. (1998). The possibility of naturalism. London: Routledge.

Bierema, L. L. (2001). Women, Work, and Learning. In T. Fenwick (Ed.), Sociocultural perspectives on learning through work (pp. 53-62). San Francisco: Jossey Bass/Wiley.

Billett, S. (2001). Learning in the workplace: Strategies for effective practice. Sydney: Allen and Unwin.

Billett, S. (2003, 1-3 December 2003). Individualising the social - socialising the individual: Interdependence between social and individual agency in vocational learning. Paper presented at the 11th Annual International conference on post-compulsory education and training: Enriching learning cultures, Gold Coast. 
Billett, S. (2004). Co-participation at work: Learning through work and throughout working lives. Studies in the Education of Adults, 36(2), 190-205.

Billett, S. (2005a). Constituting the workplace curriculum. Journal of Curriculum Studies, 37(1).

Billett, S. (2005b). Relational interdependence between social and individual agency in work and working life. Mind, Culture and Activity, 12(4).

Billett, S., Barker, M., \& Hernon-Tinning, B. (2004). Participatory practices at work. Pedagogy, Culture and Society, 12(2), 233-257.

Billett, S., \& Pavlova, M. (2003). Learning through working life: individuals' agentic action, subjectivity and participation in work. Paper presented at the 11th Annual International conference on post-compulsory education and training: Enriching learning cultures, Gold Coast.

Billett, S., \& Somerville, M. (2004). Transformations at work: Identity and learning. Studies in Continuing Education, 26(2), 309-326.

Cole, M. (1998). Can cultural psychology help us think about diversity? Mind, Culture and Activity, 5(4), 291-304.

Fenwick, T. (1998). Women's Development of Self in the Workplace. International Journal of Lifelong Learning, 17(3), 199-217.

Fenwick, T. (2002). Lady, Inc.: women learning, negotiating subjectivity in entrepreneurial discourses. International Journal of Lifelong Education, 21(2), 162-177.

Fuller, A., \& Unwin, L. (2003). Fostering workplace learning: Looking through the lens of apprenticeships. European Educational Research Journal, 2(1), 41-55.

Fuller, A., \& Unwin, L. (2002). Developing pedagogies for the workplace. In K. Evans, P. Hodkinson \& L. Unwin (Eds.), Working to learn: Transforming workplace learning. London: Kogan-Page.

Giddens, A. (1991). Modernity and self-identity: Self and Society in the Late Modern Age. Stanford: Stanford University Press.

Grey, C. (1994). Career as a project of the self and labour process discipline. Sociology, 28(2), 479497.

Hodkinson, P., \& Hodkinson, H. (2003). Individuals, Communities of Practice and the Policy Context. Studies in Continuing Education, 25(1), 3-21.

Leontyev, A. N. (1981). Problems of the development of the mind. Moscow: Progress Publishers.

Malle, B. F., Moses, L. J., \& Baldwin, D. A. (2001). Introduction: The Significance of Intentionality. In B. F. Malle, L. J. Moses \& D. A. Baldwin (Eds.), Intentions and Intentionality: Foundations of Social Cognition (pp. 1-26). Cambridge, Massachusetts: The MIT Press. 
Newman, D., Griffin, P., \& Cole, M. (1989). The construction zone: Working for cognitive change in schools. Cambridge: Cambridge University Press.

Noon, M., \& Blyton, P. (1997). The realities of work. Basingstoke, Hants: Macmillan.

Piaget, J. (1968). Structuralism (C. Maschler, trans. and ed.). London: Routledge \& Kegan Paul.

Pusey, M. (2003). The Experience of Middle Australia. Cambridge, UK: Cambridge University Press.

Ratner, C. (2000). Agency and culture. Journal for the Theory of Social Behaviour, 30(413-434).

Rogoff, B. (1990). Apprenticeship in thinking - cognitive development in social context. New York: Oxford University Press.

Rogoff, B. (1995). Observing sociocultural activity on three planes: Participatory appropriation, guided participation, apprenticeship. In J. W. Wertsch, A. Alvarez \& P. del Rio (Eds.), Sociocultural studies of mind (pp. 139-164). Cambridge, UK: Cambridge University Press.

Rogoff, B., \& Gauvain, M. (1984). The cognitive consequences of specific experiences - weaving versus schooling among the Navajo. Journal of Cross-Cultural Psychology, 15(4), 453-475.

Rose, N. (1990). Governing the soul: The Shaping of the Private Self. London: Routledge.

Scribner, S. (1984). Studying working intelligence. In B. Rogoff \& J. Lave (Eds.), Everyday cognition: Its development in social context (pp. 9-40). Cambridge, Mass: Harvard University Press.

Scribner, S. (1985a). Knowledge at work. Anthropology and Education Quarterly, 16, 199-206.

Scribner, S. (1985b). Vygostky's use of history. In J. V. Wertsch (Ed.), Culture, communication and cognition: Vygotskian perspectives (pp. 119-145). Cambridge, UK: Cambridge University Press.

Scribner, S. (1997/1990). A sociocultural approach to the study of mind. In E. Tobah, R.J. Falmagne, M.B. Parlee, L.M. Martin \& e. A.S. Kapelman (Eds.), Mind and Social Practice: Selected Writings of Sylvia Scribner. (pp. 266-280.). Cambridge, UK: Cambridge University Press

Searle, J. R. (1995). The Construction of Social Reality. London: Penguin.

Smith, R. J. (2004). Necessity in action: The epistemological agency of the new employee. Unpublished Master of Education, Griffith University, Brisbane.

Solomon, N. (1999). Culture and difference in workplace learning. In D. Boud \& D. J. Garrick (Eds.), Understanding Learning at Work (pp. 119-131). London: Routledge.

Somerville, M. (2002). Changing Masculine Work Cultures. Paper presented at the Envisioning practice -- Implementing change, Gold Coast. 
Somerville, M., \& Bernoth, M. (2001). Safe Bodies: Solving a Dilemma in Workplace. Paper presented at the Knowledge Demands for the New Economy. 9th Annual International Conference on Post-compulsory Education and Training., Gold Coast, Queensland. Valsiner, J. (1994). Bi-directional cultural transmission and constructive sociogenesis. In W. d. Graaf \& R. Maier (Eds.), Sociogenesis Re-examined (pp. 101-134). New York: Springer. Valsiner, J. (1998). The Guided Mind: A Sociogenetic Approach to Personality. Cambridge, Mass: Harvard University Press.

Valsiner, J. (2000). Culture and Human Development. London: Sage Publications.

Valsiner, J., \& van der Veer, R. (2000). The Social Mind: The construction of an idea. Cambridge, UK: Cambridge University Press.

von Glasersfeld, E. (1987). Learning as a constructive activity. In C. Janvier (Ed.), Problems of representation in the teaching and learning of mathematics. Hillsdale, NJ: Lawrence Erlbaum.

Vygotsky, L. S. (1978). Mind in society: the development of higher psychological processes. Cambridge MA, Harvard University Press.

Wertsch, J. V. (1998). Mind as Action. New York: Oxford University Press.

Williams, S. (2002). Individual agency and the experience of the New Deal. Journal of Education and Work. 15(1) pp53-74. 